\title{
Development of a Web Based Intelligent Dietetic System
}

\author{
Aderonke A. Kayode, Abidemi E. Adeniyi, Noah O. Akande \\ Department of Computer Science, College of Pure and Applied Sciences, \\ Landmark University, Omu-Aran, Kwara State, Nigeria.
}

ORCID: 0000-0001-5440-5546 (Aderonke Kayode)

\begin{abstract}
"Health is wealth" a healthy diet is the friend of the soul, everybody needs to take a healthy diet that contains equal proportions of nutrients which is very essential to basic development of human body system. This work addressed the problem encountered in everyday life, most people feed wrongly which may also sometimes lead to malnutrition that can result in various diseases. In this paper, a web based intelligent dietetic system which aids individual in picking the appropriate food content with the right nutrition that their body needs is developed. The work also helps in creating a balanced diet to an individual based on their work schedule, Body mass index (BMI), and ailment if any. This work suggests the appropriate diet for an individual with a particular type of ailment. The system create a possible list of food and fruits that will not further cause any form of harm but give aid to the healing process of such individual. This work will serve as a foundation for information on medical system that will enhance easy nutritional knowledge on what to eat and what not to eat, bringing the dietician to your door step, getting all the essential nutritional information needed without needing to be in the same office with a dietician. It will be useful to nutritionist and dieticians and enable the users to get the needed nutritional value to enhance their health status.
\end{abstract}

Keywords: Expert system, Diet, Food, Ailment, Health, Nutrition, Calorie

\section{INTRODUCTION}

Expert systems eras are advancing daily due to the efficient usage options it provides and the reliability of its applications ( $\mathrm{Li}$ et al., 2002). The need for medical science and artificial intelligence (AI) automation to combine cannot be over emphasized, but they are almost beginning to overlap upon each other and in certain situations (Kayode et al, 2019, Oladele et al 2019). As humans across the planet are becoming increasingly cognizant of their weight, eating progressively sound regimens and staying away from low quality nourishment is essential for healthy living, a framework that can quantify calories and sustenance in our ordinary suppers will be extremely helpful for keeping up our wellbeing (Chen et al., 2012).

Chronic diseases like polygenic disease, hypertension, diabetics, coronary artery disease and cancer are traceable to diet. As the world is becoming more nutrition and health conscious, it is necessary to create an easy platform were the users can get easy access to a quick and reliable dietitian and to make sure that the information and knowledge about what to eat in order to be healthy gets across the globe. Right Diet is necessary anywhere in the world; diet influences explicit results that are significant for an individual achievement (Bermudez, 2012). Lacey and Pritchett (2003) reported that overall nutrition affects the total performance of adolescents; the work emphasized that there is a strong relationship between eating rightly and individual's day to day execution of work. So it was concluded that diet plays a vital role in our day to day work execution.

Undesirable eating regimen in grown-ups and kids is a noteworthy medical issue in developing nations (Chen et al., 2012). Poor eating is correlated with lower performance at work, school and every area of life, increased fatigue and vulnerability to illness. Other aftereffects include irritability, anxiety, difficulty concentrating, sleep disturbance, an increased risk of depression and menstrual problems in women. A sustenance calorie and nourishment estimation framework is exceptionally advantageous and important for everybody to measure and manage the daily food intake in our day to day lives.

The proposed system contains the knowledge and information with respect to the wellness of an individual. We additionally alluded information required to create the database, information like work schedule, weight of the individual, height, health status and age is inputted in the database. This work consist of the user interface which will be publically displayed on the website, the intelligent dietician consists of a robot (bot) implemented with insight about human weight control plans. It acts as a diet advisor like an expert dietician.

It is essential for an individual to maintain good health and body condition especially while they work. In fact, a very well-planned diet is very important for an individual for effective response to their daily activities (Myers, 2008). At the point when the body doesn't get enough vitality, protein and different supplements, it ends up malnourished and leads to slower wound healing, weakness, withered bone, and hindered working of the guts and lungs (Kuo et al., 2007). 
The uniqueness of this work is that it asks for all the user's relevant details such as the age, height, weight, age, level of activity, ailment and other related data to calculate the user's Body Mass index (BMI) and classify the user based on their BMI and finally process the supplement value expected to suit their needs.

\section{MATERIAL AND METHOD}

The proposed work is a web based intelligent dietetic system which is implemented using the C++ Expert System Shell and the $\mathrm{C}++$ programming language running on a Window Web Server. JavaScript programming language was used to build the BMI calculator and AI functionality. PHP was used in the server side interaction.

The system calculates the BMI and uses dietary information from Bermudez 2012. The system is developed to calculate appropriate calories/nutrients the users require based on certain information that will be required by the user to provide, in order for the system to appropriately advise them based on the given input. This system also centers on ailments like high blood pressure and diabetes, it gives appropriate diet for any user with the ailments mentioned above.
The web page will have a log-in page where the user will need to sign in with a user name and password that will be made known only to them. The next page will consist of certain questions that the user will need to answer in order for the system to appropriate the correct diet for the user. Such questions include;

(i) Name

(ii) Age

(iii) Level of activity

(iv) Weight

(v) Height

(vi) Ailment (if any) etc...

To develop proper diet intake, from the above data, body mass index (BMI) calculator which calculates the BMI based on the user's height and weight is implemented. Also, An AI bot functionality using java script is implemented. The AI bot interacts with the user so as to know the amount of energy an individual burns and the amount of calories needed to keep the individual healthy and helps in calculating the necessary nutritional value needed to match their calories output is included.

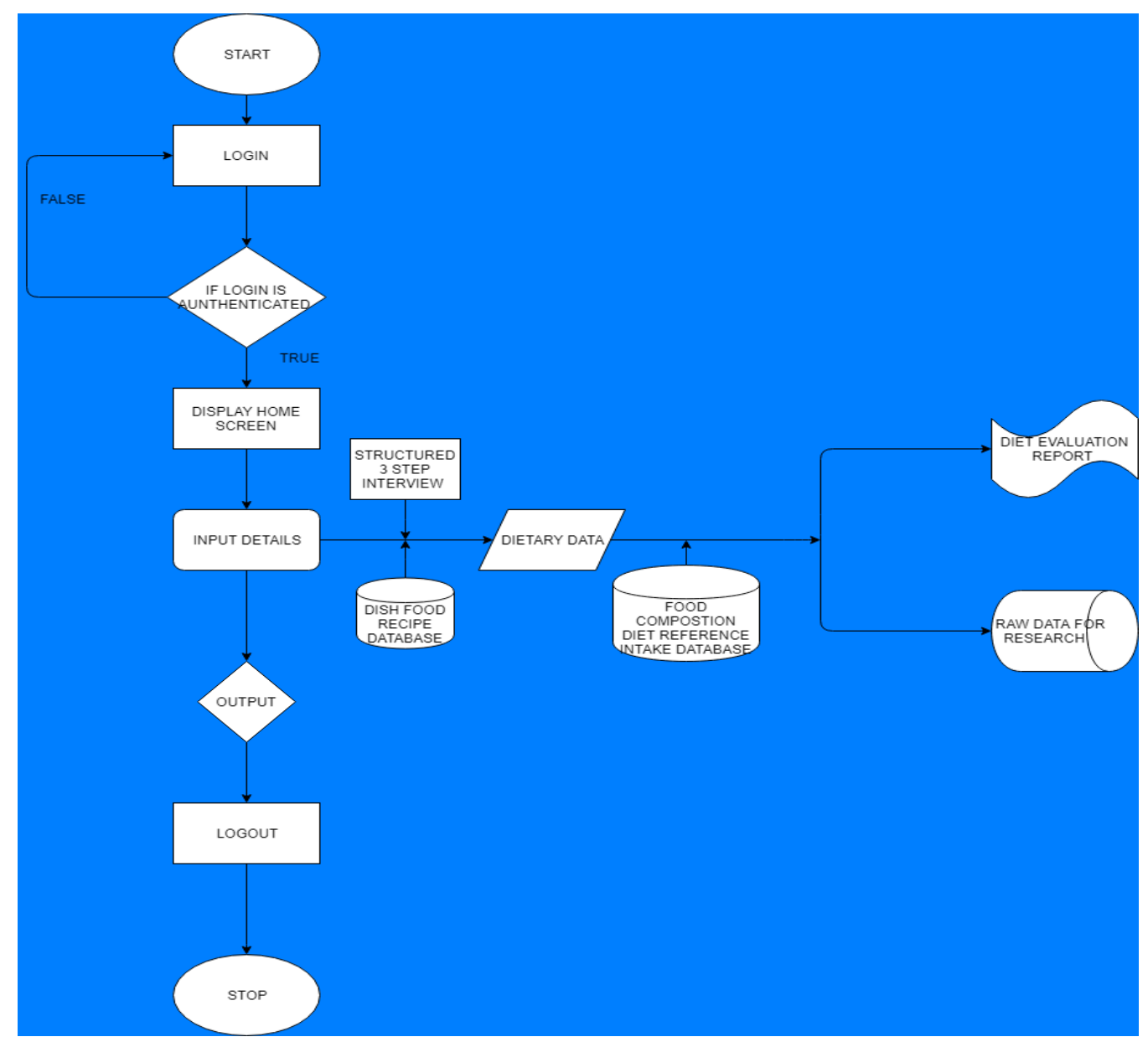

Figure 1: Proposed System Flowchart 


\section{EXPERIMENTAL RESULT AND DISCUSSION}

This section contains the experimental result of the proposed system, the screenshot of output, interface and basic requirement needed to effectively implement the system. Figure 2 presents the interface where the user supply the inputs (height and weight needed) to calculate the BMI. Figure 3 displays the individuals body mass index (BMI) result and lets you know if you are overweight, underweight, obessed or healthy weight.

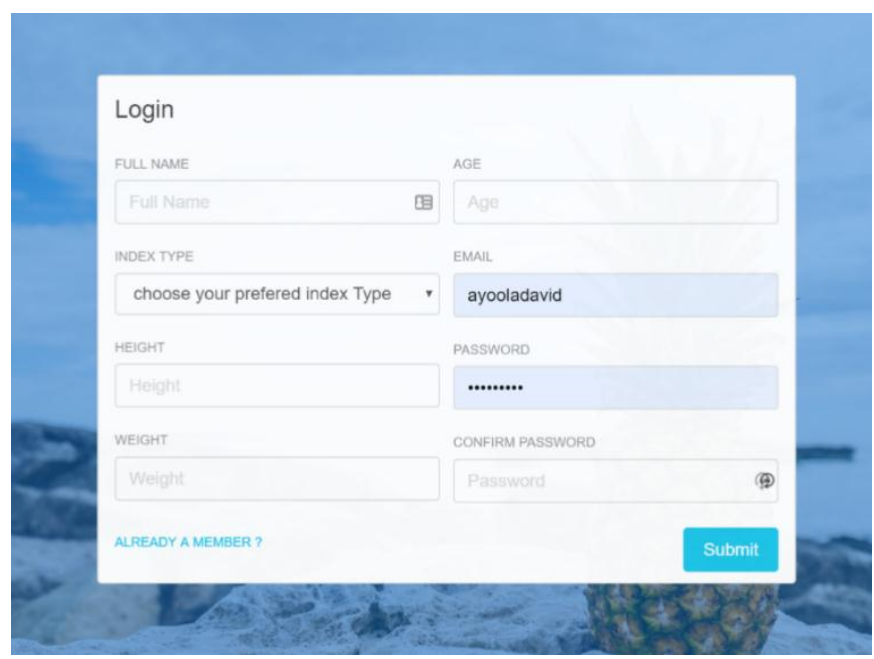

Figure 2: inputs to calculate the BMI of the user.

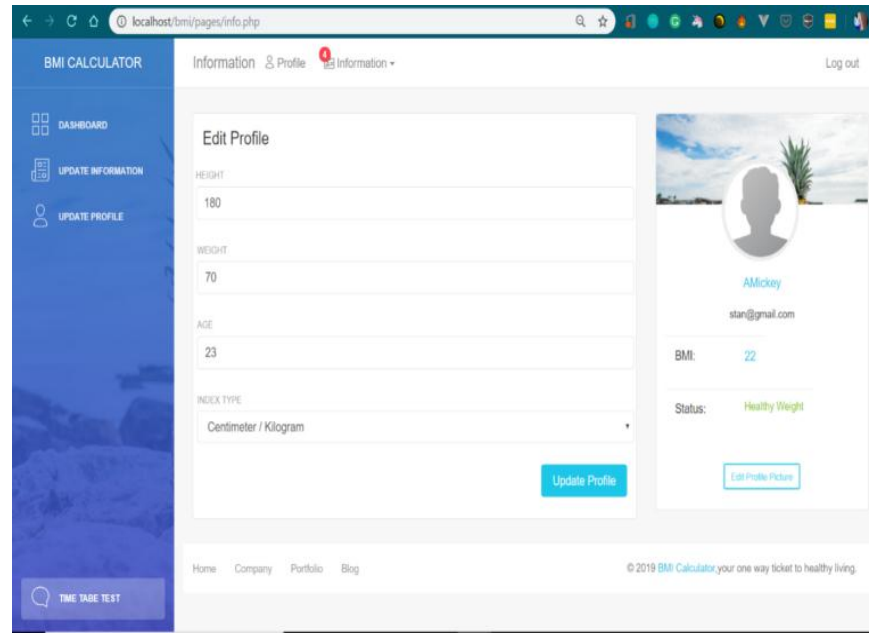

Figure 3: BMI result

\subsection{Three-way AI interview}

The three-way interview (depicted in Figure 4) is to know the amount of energy an individual burns and the amount of calories needed to help keep the individual healthy. After the three way Interview, the AI generates a meal time table suitable for the individual to keep him/her healthy based on his/her BMI, level of activity and ailment (if any), as shown in Figure 5.
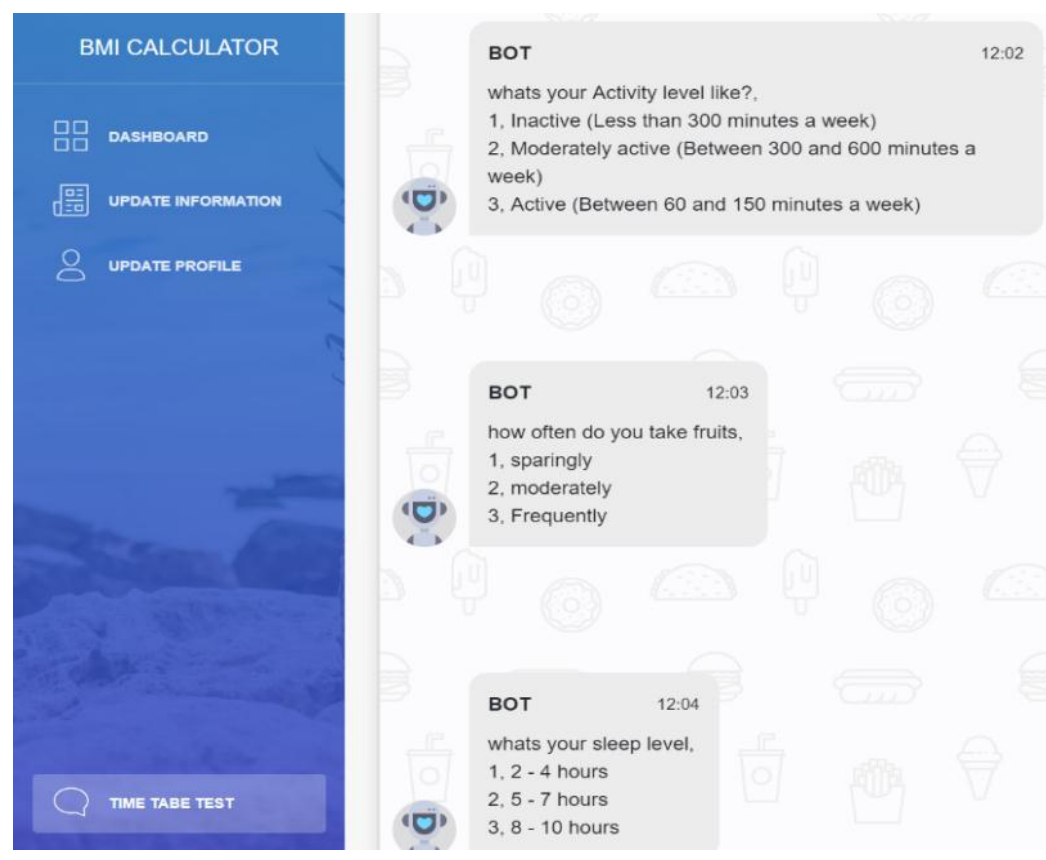

Figure 4: The three-way AI interview 


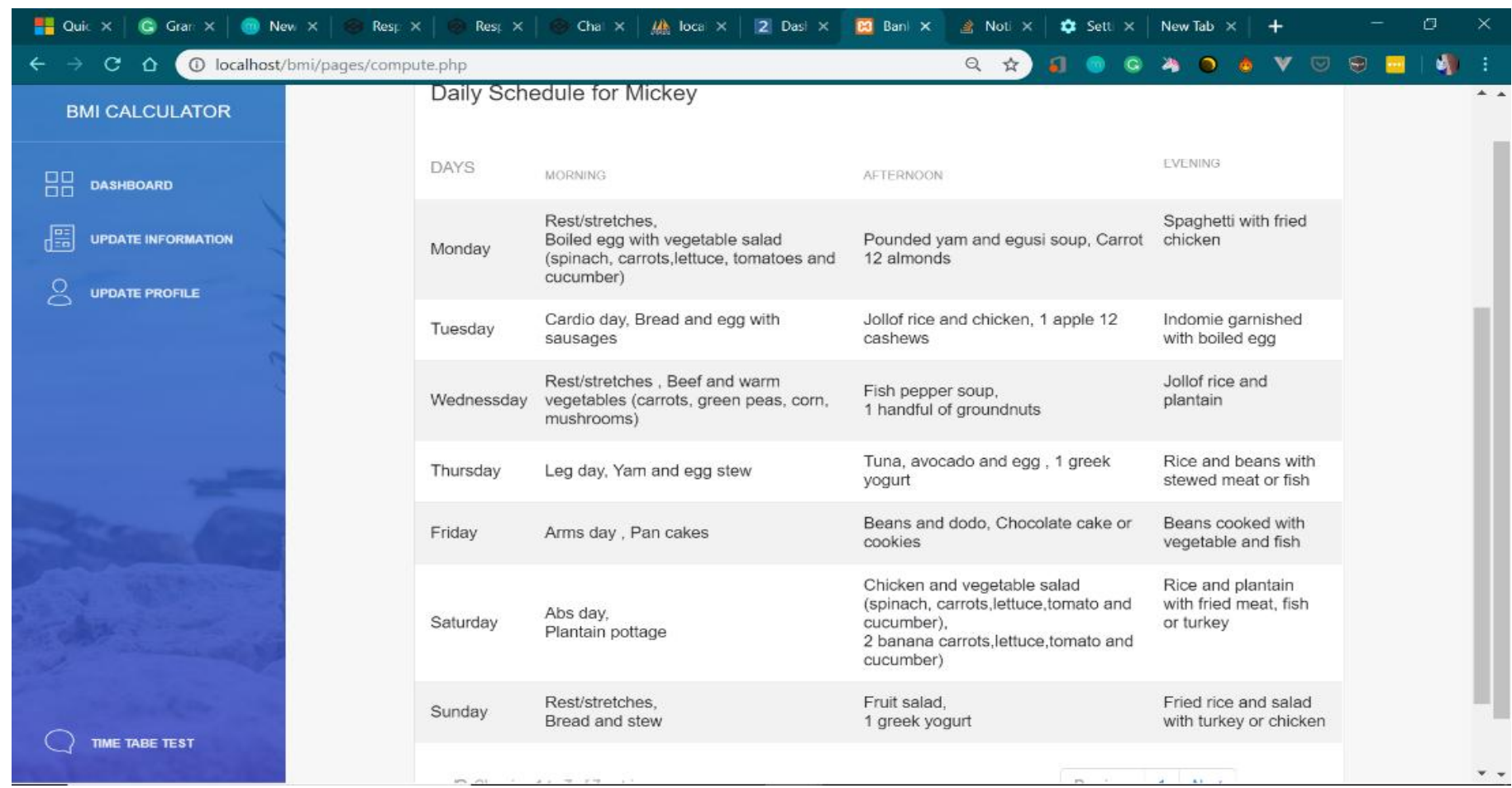

Figure 5: Sample of food time table generated by the AI

\section{PERFORMANCE GOAL}

The system performance goal is discussed in Table 1

Table 1: System performance goal

\begin{tabular}{|c|l|l|}
\hline Indicator & \multicolumn{1}{|c|}{ Result } & \multicolumn{1}{|c|}{ Existing System } \\
\hline Action & $\begin{array}{l}\text { The web-based } \\
\text { intelligent dietetic } \\
\text { system is opened to users } \\
\text { to check the appropriate } \\
\text { meal time table suitable } \\
\text { for the individual to keep } \\
\text { him/her healthy based on } \\
\text { his/her BMI and ailment } \\
\text { (if any). }\end{array}$ & $\begin{array}{l}\text { Existing system is } \\
\text { not web-based } \\
\text { system. Only the } \\
\text { administrator has the } \\
\text { access to the system. }\end{array}$ \\
\hline Cost & $\begin{array}{l}\text { No extra cost of } \\
\text { implication for the } \\
\text { operation and usage of } \\
\text { web-based system }\end{array}$ & $\begin{array}{l}\text { Application } \\
\text { developed }\end{array}$ \\
\hline Usage & $\begin{array}{l}\text { It can be used at any } \\
\text { time by anybody since } \\
\text { its web-based }\end{array}$ & $\begin{array}{l}\text { It is to be used when } \\
\text { the administrator is } \\
\text { physically available. }\end{array}$ \\
\hline
\end{tabular}

\section{CONCLUSION AND RECOMMENDATION}

In this study, an intelligent dietetic system which is a web based application was developed to improve existing diet systems. An Intelligent Dietetic system that works efficiently was proposed and implemented. It is secure and essential; the experimental result shows that the system works effectively for every gender and age category. Future works can use other techniques or algorithms to improve the way humans eat and guarantee a longer life span and put an end to malnourishments.

\section{ACKNOWLEDGEMENTS}

Authors' appreciation goes to Centre for Research and Development, Landmark University, Omu-Aran, Nigeria for fully sponsoring the publication of this article. We also thank all authors whose work are cited and listed.

\section{REFERENCES}

[1] Bermudez, O. I., Lividini, K., Smitz, M. F., and Fiedler, J. L., 2012, "Estimating micronutrient intakes from Household Consumption and Expenditures Surveys (HCES): an example from Bangladesh," Food and nutrition bulletin, 33(3_suppl2), S208-S213.

[2] Chen, Y., Hsu, C. Y., Liu, L., and Yang, S., 2012, "Constructing a nutrition diagnosis expert system," Expert Systems with Applications, 39(2), 21322156.

[3] Chen, Y., Hsu, C.Y., Liu, L. and Yang, S., 2012. Constructing a nutrition diagnosis expert system. Expert Systems with Applications, 39(2), pp.2132-2156.

[4] Kayode, A. A., Akande, N. O., Adegun, A. A. and Adebiyi, M. O., 2019, "An Automated Mammogram Classification System using Modified Support Vector Machine," Medical Devices: Evidence and Research (MDER) 12:275 -284 
[5] Kaysen, G. A., 2000, "Malnutrition and the acute-phase reaction in dialysis patients - how to measure and how to distinguish," Nephrology Dialysis Transplantation, 15(10), pp.1521-1524.

[6] Kuo, H. W., Tsai, S. S., Tiao, M. M., and Yang, C. Y., 2007, "Epidemiological features of CKD in Taiwan," American journal of kidney diseases, 49(1), 46-55.

[7] Lacey, K. and Pritchett, E., 2003, "Nutrition care process and model: ADA adopts road map to quality care and outcomes management," Journal of the Academy of Nutrition and Dietetics, 103(8), pp.10611072.

[8] Li, D., Fu, Z., \& Duan, Y. (2002). Fish-Expert: a webbased expert system for fish disease diagnosis. Expert systems with Applications, 23(3), 311-320.

[9] Myers, F., 2008, "Nutrition care process part II: Using the International Dietetics and Nutrition terminology to document the nutrition care process," Journal of the American Dietetic Association, 108(8).

[10] Oladele, T. O. Ogundokun, R. O., Kayode, A. A., Adegun, A. A. and Adebiyi, M. O., 2019, "Application of Data Mining Algorithms for feature selection and prediction of Diabetic Retinopathy," Lecture Notes in Computer Science. Vol. 11623. 